\title{
Miao Fengchun,
}

PhD, ICT in Education Manager UNESCO

Paris, France

f.miao@unesco.org

\section{Tatiana Nanaieva,}

Intel Corporate Affairs Manager in Ukraine, Georgia \& CIS

Kyiv, Ukraine

tatiana.nanaieva@intel.com

\section{ENSURING EFFECTIVE USE OF ICT INTEACHING AND LEARNING}

The article delineates UNESCO's vision about the role, challenges and opportunities of ICT in modern education. It analyzes the impact of ICT on equal access to quality education, possibilities of open educational resources and systems, the need to rethink approaches to assessment of the quality of education and the role of teachers, challenges and opportunities of distance education, etc. The article determines that the main factors which make possible the effective implementatio $n$ of ICT in education are the result-oriented information and communication technologies in education policy, pupil-centered and student-centered ICT learning environment and individualized couching pedagogy. It is pointed to the need for creating government policy for transformation of education with ICT and its implementation at all levels of education.

Key words: distance education, ICT learning environment, modern education.

\section{Introduction}

Information and Communication Technologies (ICTs) have transformed many aspects of our lives and offered many opportunities and challenges for education. Education institutions, at all levels, need to provide every citizen with the knowledge, skills 
and competences as well as the lifelong learning opportunities required for living and working in an increasingly technology-rich environment.

Increasingly, high-speed, affordable broadband connectivity to the Internet is seen as a foundation stone of modern society. Broadband, which has been widely adopted to enable cloud computing and support the rapid processing of big data, is no longer the peripheral infrastructure, it tends to transform our relation to knowledge, to learning and even the concept of development. According to the study of the International Telecommunication Union (ITU) (ITU, 2012) based on the data of the World Bank of 2009, in Low, Middle and High-income Economies (except OECD countries and the United States), 10\% increase in broadband penetration yielded an additional 1.21-1.38 percentage points of GDP Growth. Schools, universities, and non-formal education institutions should also ensure that they are able to exploit the potential benefits of broadband connectivity, penetrated mobile devices, and big data to expand access to, and enhance the quality and relevance of, learning throughout life, including through transforming education management, teaching and learning towards needs of individual fulfillment and sustainable development of knowledge economies.

The debate on the power of technology to transform education is not new; yet, in spite of massive investments, the actual impact of ICT on the way schools work and on learning outcomes remains limited. In spite of such realism the recent acceleration of technological change, including Internet developments, mobile technologies, cloud computing as well as the rise of open education resources, to cite a few examples, result in a renewed, even stronger interest in their potential to solve the structural problems of existing education systems around the world but also to stimulate new models of teaching and learning and bring education into a new era of technology enabled lifelong learning for all. Further research needs to be undertaken to provide evidence-based policy recommendations on leverage emerging ICTs to support equitable and quality education.

\section{ICT in the Education 2030 Agenda}

UNESCO convened the World Education Forum 2015 (WEF 2015) in Incheon, Republic of Korea from 19-21 May 2015 to conclude the debate on vision for education 2030. The Incheon Declaration was adopted during WEF 2015, which specified the vision and proposed 
the sustainable development goal (SDG) on education by 2030. The agreed vision is to transform lives through education, recognizing the important role of education as a main driver of development and in achieving the other proposed SDGs. This new vision is fully captured by the SDG 4 on education that was proposed by UNESCO to UN Assembly, "Ensure inclusive and equitable quality education and promote lifelong learning opportunities for all" and its corresponding targets. The $70^{\text {th }}$ Session of the United Nations General Assembly held from 22 to 30 September, adopted the proposal of SDG4 on education. The adopted Education 2030 Agenda promotes a broad and lifelong learning perspective that aims at enabling and empowering people to meet their right to quality education and fulfill their personal expectations for a life and work and contribute to the achievement of their societies' socio-economic development objectives. In such vision, ICT will have an important role to play to ensure that all young people and adults have equitable opportunities to access and complete formal and non-formal technical and vocational education and training relevant to the world of work as well as lifelong learning opportunities that enable learners to acquire diverse and relevant knowledge and skills that foster their professional and personal development. The Incheon Declaration made the following statement on the potentials of ICT to achieve Education 2030: "To achieve the goal of Inclusive and Equitable Quality Education and Lifelong Learning by 2030, ICT must be harnessed to strengthen education systems, knowledge dissemination, information access, quality and effective learning, and more efficient service provision, through the following lines of action."

To unleash potentials of ICT in underpinning the achievement of post2015 education targets, policy makers need to understand ICT's role in delivering equitable and quality lifelong learning opportunities, and the sector-wide strategies of integrating ICT in the post-2015 education agenda need to be informed by debates between education and ICT sectors. It is against this context, UNESCO, with the support from the Government of the People's Republic of China, organized the International Conference on ICT and Post-2015 Education from 23 to 25 May 2015 in Qingdao, China. The Qingdao Declaration on leveraging ICT to achieve Education 203 was adopted by the conference and released. The Qingdao Declaration reaffirmed the transformative powers of ICT under the context of Education 2030 agenda in the following areas: 


\section{Access and Inclusion}

ICT Technology offers unprecedented opportunities to reduce the long existing learning divide. The application of ICT is essential if we are to deliver on our commitment in the Incheon Declaration to non-discrimination in education and gender equality and women's empowerment for sustainable development. Governments and partners should commit to ensure that all girls and boys have access to connected digital devices and a relevant and responsive digital learning environment by 2030 , irrespective of their disabilities, social or economic status or geographic location. All education stakeholders should recognize the enrollment in quality-assured online courses as an alternative or a complementary mode to the regular programs of study when striving for the objectives of universal access to basic education and skills development.

\section{Open Educational Resources and Open Solutions}

Open Educational Resources (OERs) provide education stakeholders with opportunities to improve the quality of, and expand the access to, textbooks and other forms of learning content, to catalyze innovative use of content, and to foster knowledge creation. Governments and partners should commit to develop sector-wide strategies and capacity building programs to fully realize the potentials of OERs to expand access to lifelong learning opportunities, and to achieve quality education. All education stakeholders to facilitate access to Open Access (OA) Journals in Education for teachers, researchers and learners, and to fully evaluate the potential of Free and Open Source Software (FOSS) and Open Standards for the development of ICT solutions especially for learners with disabilities, and for learning mother-tongue languages.

\section{Quality Learning}

Governments and partners should commit to develop well-informed long-term policies and strategies to unleash the potential of ICT to achieve greater quality in education and transform learning. To ensure effective use of ICT for high-quality learning, there is a need to redefine learning outcomes and the way we organize and assess learning if we want our education systems to prepare lifelong learners - whether children or adults - to thrive in networked knowledge societies and succeed in economies that are increasingly reliant on technology. 
The ability to leverage ICT for learning is no longer a specialized skill, it is foundational to success in modern society. It's imperative to integrate basic ICT skills and information literacy in primary and secondary education curricula including the emergent requirements of the ICT-rich environments on literacy and numeracy, and on inter- and transdisciplinary learning outcomes. The learning assessment must be reformed in order to reflect the use of ICT and its impact on learning and on outcomes.

Successful integration of ICT into teaching and learning requires rethinking the role of the teachers and reforming their preparation and professional development. Governments and partners should therefore ensure that teacher training institutions are equipped and prepared to use ICT adequately to expand the benefits of training and professional development programs to all teachers and to act as the vanguard for technology-supported innovations in education. Governments and partners should also commit to provide teachers with system-wide support for the pedagogical use of ICT, to incentivize teacher innovation, and to develop networks and platforms that allow teachers to share experiences and approaches that may be of use to peers and other stakeholders.

\section{Lifelong Learning Pathways}

Lifelong learning is the guiding principle to enhance individual's knowledge, skills and competences for work and life. ICT should be used to deliver education and training in both formal and non-formal settings, anytime and anywhere. As it can improve and diversify learning pathways, improve quality and further reach vulnerable and underserved groups including rural youth and adults, women and girls, out-of-school youth, and people with disabilities.

\section{Online Learning Innovations}

The challenges linked to quality assurance, pedagogical effectiveness and certification of online learning remain huge, but the benefits of well-organized online learning courses for university students and other groups of learners have increasingly recognized. Online learning, including in the form of Massive Open Online Courses (MOOCs), has the potential to build new learning pathways towards tertiary education and lifelong learning. Governments, institutions and other stakeholders further consider and harness the opportunities brought by online learning innovations. 
Governments and partners should make efforts made to explore the potential of big data for enhancing online learning to inform our understanding of students' behavior and learning and to improve the design and organization of online courses. In that context, governments need to develop policies and systems to ensure secure, appropriate, and ethical use of data, including safeguarding the privacy and confidentiality of students' personally identifiable information.

\section{Quality Assurance and Recognition of Online Learning}

Governments and partners should establish transparent quality assurance measures of on-line learning that support reliable, valid and credible assessment. They should recognize the potential of innovative ICT-based approaches in certification and assessment, including competency, portfolio, online badging and peer assessment, as tools which can broaden routes to employment, fulfillment and achievement of qualifications by all learners. Governments should also give fair and transparent recognition of learning outcomes and qualifications acquired through on-line learning. Governments and partners including education and training providers should use ICT to promote recognition, validation and accreditation of knowledge, skills and competencies acquired through informal and non-formal settings and build bridges between formal, nonformal and informal learning.

\section{Monitoring and Evaluation}

Governments and partners should commit to develop comprehensive national monitoring and evaluation systems to generate sound evidence for policy formulation regarding the integration, use and impact of ICT in education to enhance the management of education systems as well as to ensure accountability, and understand the key roles that ICT increasingly play in the transmission of knowledge, the acquisition of new skills and competencies, and the development of values and attitudes that are relevant to the building of sustainable and peaceful societies.

Governments and partners should also support capacity development in data collection, analysis and reporting at the country, regional and global levels, based on the ICT in Education Indicators developed UNESCO Institute for Statistics (UIS). Governments and partners should seek to reinforce and sustain efforts to establish the appropriate national level mechanisms and processes. 
Enabling Factors for Effective Use of ICT for Teaching and Learning

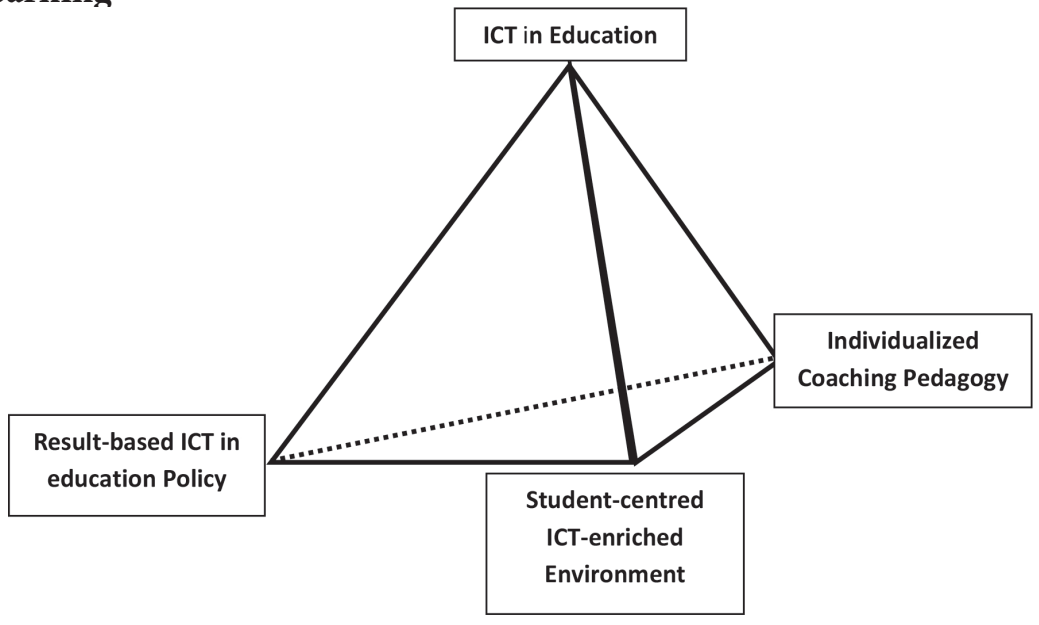

Multi-Entry Approach to ICT in Education Policy Development

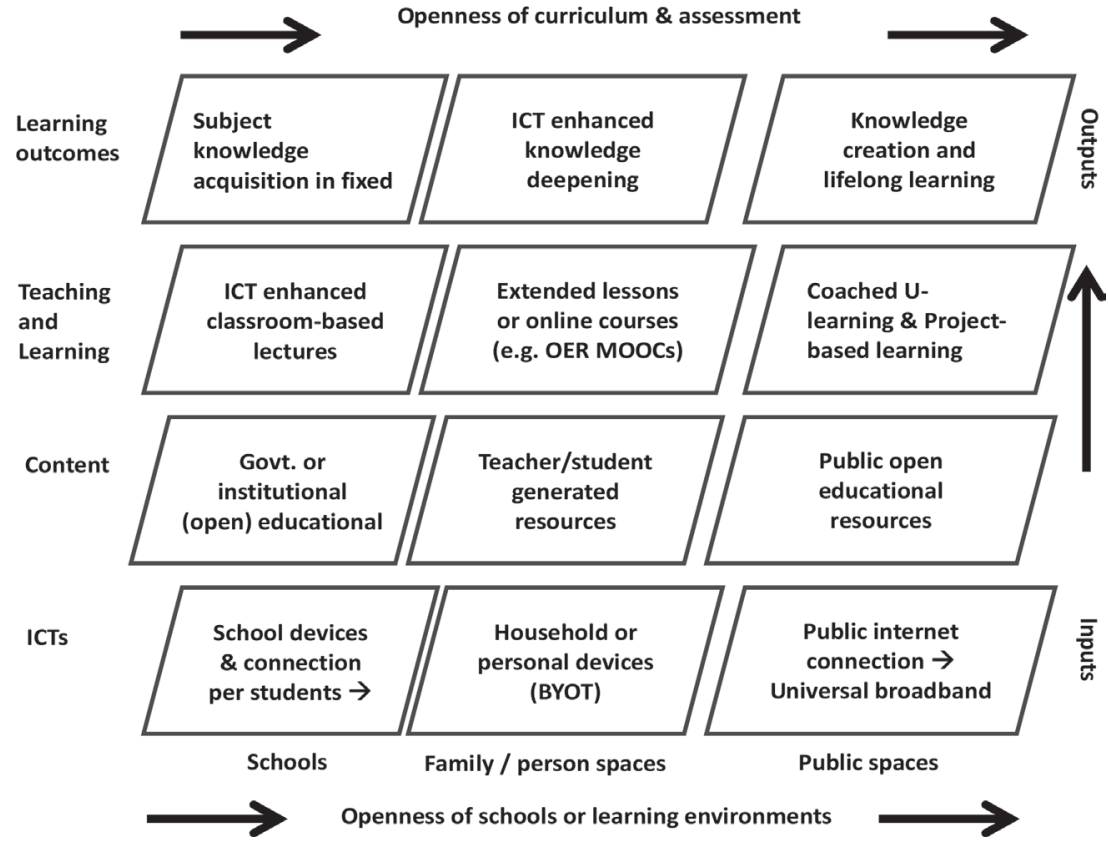


In order to make successful use of ICT in enhancing the reach and quality of teaching and learning, policy makers need to be aware of how ICT can be of best value in their country's education system, and need to develop a supportive policy environment and framework at the national level for the integration of ICT into their education systems.

Rapid developments in information and communication technologies (ICT) in recent years have resulted in significant changes in the way the world operates and communicates. This in turn has had an impact on educational needs, both in terms of the content and the delivery of educational services, and there has been increasing pressure on decisionmakers to acquire new technologies. At the same time, forms of ICT are multiplying with an increasing array of ICT options for decision-makers to choose from when integrating ICT into education.

Faced with this situation, policy makers in many countries thought that to simply equip schools with PCs and train teachers in their use would prepare pupils for the demands of the $21^{\text {st }}$ century. We know, however, that simply providing access to ICT is not going to radically change education systems for the better. An overall view of what education should be seeking to achieve is needed in order for ICT to be utilized to their full potential within education systems. Decision makers and policy makers need to formulate appropriate policies based on their specific situation and educational goals.

The "ICT in Education" policies of different countries vary greatly. While some of them have not yet formulated any specific visions or plans, others are at an advanced stage of ICT integration, that is, they are focusing on the meaningful integration of ICT (including radio, television and DVD) into teaching and learning processes.

It is a UNESCO concern to ensure that ICT does not become a source of further inequality, with the digital divide accentuating already existing disparities. Access to computers, the Internet, and the capacity to make use of ICT are related to factors such as socioeconomic status, ethnic background, gender, age, educational background and geographical location. It is important that education policies acknowledge the gap and promote ICT in ways that will not widen the gap further.

\section{UNESCO and Intel Online Tools and Resources on ICT Education Policy Development}

To ensure a really effective use of ICT in teaching and learning the decision makers face the need to develop the efficient education 
policy of education transformation with ICT. Otherwise multiple ICT related projects, even being pretty efficient separately, may not bring really effective positive outcome in the country.

UNESCO and Intel have recently developed a joint online platform "ICT in Education Policy" to support countries in their efforts of discussing forward-thinking plans and policies of efficient education transformation with ICT. This platform is designed to meet the needs of people really interested in the field of ICT in education, such as ministry officials, academia, practitioners and other stakeholders, who are welcomed to freely access resources, news, events, and engage in policy discussions worldwide [6].

The UNESCO-Intel ICT in Education Policy Platform offers learning and working space dedicated to the development of ICT in education policies with a view to empowering lifelong learners which was discussed earlier in this article. The Platform is designed as a one-stop referral website with readily available, expertly selected information and resources.

The online toolkits, the Intel Education Transformation Policy Tool and the UNESCO ICT in Education Toolkit, are key policy development resources. They will guide users through the policy development process, and provide a comprehensive set of tools to improve the workflow of policy making. The Platform seeks to provide a one-stop reference with information and resources selected and organized by experts. Resources are provided to help stakeholders deepen their understanding of ICT in education policymaking and support their policy development process.

We are open to work together to unleash the potential and improve the context of use of ICT in education in each of your respectful countries, to support your efforts in developing national "ICT in Education Policies" to enable the positive change in developing a new type of workforce in the digital age and country growth.

\section{REFERENCES}

1. ITU (2013). Impact of Broadband on the Economy: Research to Date and Policy Issues.

https://www.itu.int/ITU-D/treg/broadband/ITU-BB-Reports_Impact-ofBroadband-on-the-Economy.pdf 
2. UNESCO (2015). Qingdao Declaration.

http://unesdoc.unesco.org/images/0023/002333/233352E.pdf

3. UNESCO Guide to Measuring ICT in Education.

http://www.unesco.org/new/en/unesco/themes/icts/policy/indicators/

4. World Education Forum 2015.

https://en.unesco.org/world-education-forum-2015/incheon-declaration

5. UNESCO ICT Competency Framework for Teachers.

http://unesdoc.unesco.org/images/0021/002134/213475e.pdf

6. ICT in Education Policy.

https://www.ictedupolicy.org/ 